\title{
Borehole water-level variations and the structure of the subglacial hydrological system of Haut Glacier d'Arolla, Valais, Switzerland
}

\author{
B. P. HubBard, \\ Centre for Glaciology, Institute of Earth Studies, University of Wales, Aberystwyth, Dyfed Sr23 3DB, Wales \\ M.J. Sharp, \\ Department of Geography, University of Alberta, Edmonton, Alberta T6G 2H4, Canada \\ I. C. Willis, M. K. NielseN, \\ Department of Geography, University of Cambridge, Cambridge CB2 3EN, England \\ C. C. SMART \\ Department of Geography, University of Western Ontario, London, Ontario N6A 5C2, Canada
}

\begin{abstract}
Late-summer subglacial water pressures have been measured in a dense array of boreholes in the ablation area of Haut Glacier d'Arolla, Switzerland. Interpolated surfaces of minimum diurnal water pressure and diurnal water-pressure variation suggest the presence of a subglacial channel within a more widespread, distributed drainage system. The channel flows along the centre of a variable pressure axis (VPA), some tens of metres wide, that is characterized by low minimum diurnal water pressures (frequently atmospheric) and high diurnal water-pressure variations. These characteristics are transitional over a lateral distance of c. $70 \mathrm{~m}$ to higher and more stable subglacial water pressures in the adjacent distributed system. Waterpressure variations recorded in borcholes located close to the centre of the VPA reflect the delivery of surface-derived meltwater to the glacier bed and result in a diurnally reversing, transverse hydraulic gradient that drives water out from the channel into the distributed system during the afternoon and back to the channel overnight. Subglacial observations suggest that such flow occurs through a vertically confined sediment layer. Borehole turbidity records indicate that the resulting diurnal water flows are responsible for the mobilization and transport of fine debris in suspension. Analysis of the propagation velocity and amplitude attenuation of the diurnal pressure waves suggests that the hydraulic conductivity of the sediment layer decreases exponentially with distance from the channel, falling from c. $10^{4} \mathrm{~m} \mathrm{~s}^{-1}$ at the channel boundary to c. $10^{7} \mathrm{~ms} \mathrm{~s}^{-1} 70 \mathrm{~m}$ away. These apparent hydraulic conductivities are consistent with Darcian flow through clean sand and typical glacial till, respectively.

We suggest that fine material is systematically flushed from basal sediments located adjacent to large, melt-season drainage channels beneath warm-based glaciers. This process may have important implications for patterns of glacier erosion, hydrochemistry and dynamics.
\end{abstract}

\section{INTRODUCTION}

Warm-based glaciers may drain subglacially via a number of different hydraulic configurations. These may be classified as either "discrete" or "distributed". The former may be composed of channels incised upwards into ice (Röthlisberger, 1972; Hooke and others, 1990) or downwards into bedrock (Nye, 1973). In each case, channels link to form efficient networks with the capacity to drain large amounts of meltwater rapidly. In contrast, distributed systems drain extensive areas of the glacier bed at lower flow rates. Such flow may occur via meltwater films (Weertman, 1957, 1972), through permeable subglacial sediments (Boulton, 1974; Clarke, 1987) or via networks of either linked cavities over bedrock (Walder, 1986; Kamb, 1987) or "canals" above and within unconsolidated sediments (Walder and Fowler, 1994). The existence of these different drainage configurations has been established empirically on the basis of proglacial bedrock mapping (e.g. Walder and Hallet, 1979; Sharp and others, 1989), dye-tracer studies (e.g. Seaberg and others, 1988), meltwater hydrochemistry (e.g. Fountain, 1992) and observations at the glacier bed (e.g. Kamb and LaChapelle, 1964). 
A full understanding of the co-existence of, and interaction between, these different subglacial drainage systems may be critical to models of glacier motion, since each configuration may be characterized by a distinctive steady-state relationship between discharge and water pressure (e.g. Röthlisberger, 1972; Walder, 1986). The stability of distributed flow to channel development has therefore been investigated for films (e.g. Walder, 1982; Weertman and Birchfield, 1983), permeable sediments (e.g. Alley, 1992) and linked cavities (Kamb, 1987). Kamb (1987) argued that certain linked-cavity geometries are inherently unstable to perturbations in subglacial water pressure and suggested that transitions between drainage via tunnels at relatively low steady-state water pressures) and linked cavities (at relatively high steady-state water pressures) may be responsible for the initiation and termination of glacier surges. Subglacial drainage systems beneath temperate glaciers may therefore develop or collapse in response to seasonal variations in meltwater supply (e.g. Hock and Hooke, 1993). Whilst a widespread distributed system can evacuate base flows during the winter, the onset of high and variable melt-season discharges may destabilize such a system and replace it, at least locally, with channelized drainage. This replacement may occur at glaciers that are underlain by bedrock or unconsolidated sediments (e.g. Fountain, 1992, 1994). Dye-tracer studies at Haut Glacier d'Arolla provide strong empirical support for this model, indicating, first, that channelized drainage develops as the headward growth of channels replaces distributed flow during the melt season, and secondly, that the boundary between the two systems is associated with the retreat of the snow line at the glacier surface (Nienow, 1994). Analysis of subglacial piezometric surfaces indicates that such replacement is laterally variable, with distributed drainage surviving the melt season in areas of the glacier bed separating the channels (Fountain, 1994). Reduced surface melting during the winter results in the creep closure of melt-season channels and the re-establishment of a widespread distributed drainage system (paper in preparation by I. C. Willis and others).

Evidence from warm-based glaciers therefore indicates that the spatial extent of channelized and distributed drainage configurations varies seasonally and that the two co-exist at the glacier bed for much of the melt season, irrespective of the nature of the substrate. However, little is known about the transition between these drainage components or the manner in which they interact hydraulically. Borehole investigations provide a means of addressing such issues, since they allow spatially distinct drainage components to be accessed and studied simultaneously. In this paper, we present diurnal records of subglacial water pressure, electrical conductivity (EC) and turbidity recorded at the base of a dense network of boreholes drilled to the bed of Haut Glacier d'Arolla, Switzerland. Spatial variations in these properties are interpreted in terms of the presence of different subglacial drainage configurations and the nature of the hydraulic linkages between them.

\section{FIELD SITE AND METHODS}

Haut Glacier d'Arolla is a predominantly warm-based valley glacier located at the head of Val d'Hérens, Valais,
Switzerland (Fig. 1). The glacier extends from c. $2560 \mathrm{~m}$ a.s.l. at its snout to c. $3500 \mathrm{~m}$ a.s.l. at its headwall and covers an area of c. $6.3 \mathrm{~km}^{2}$. A dense array of 24 boreholes was drilled during July and August 1993 close to the eastern margin of the ablation area of the glacier, about $1.5 \mathrm{~km}$ from the terminus (Fig. 2). This site was chosen on the basis of reconstructed subglacial hydraulic potentials that predicted the presence of a major melt-season channel beneath this part of the glacier (Sharp and others, 1993). Ice-marginal and subglacial observations invariably reveal that the glacier is underlain by unconsolidated sediments. The recovery of such sediment within and on borehole probes further indicates that such a substrate extends beneath the borehole array. It is unlikely that the debris recovered on these probes was derived from the melting of debris-rich basal ice, since no thick basal-ice layers have been observed at the glacier (Hubbard, 1992). Available evidence therefore indicates that Haut Glacier d'Arolla is underlain by unconsolidated sediments.

Boreholes were drilled to the glacier bed using hot water. The bed was considered to have been reached and drilling was halted when no further progress could be made at a depth consistent with radio-echo sounding (Sharp and others, 1993) and the depths of neighbouring boreholes. Borehole depths varied from $23 \mathrm{~m}$ for borehole 38 , located close to the glacier margin, to $142 \mathrm{~m}$ for borehole 46 , located towards the glacier centre line (Fig. 2). Inclinometry of 12 of these boreholes indicated a mean horizontal deviation of $2.9 \pm 0.7 \mathrm{~m}$ across the glacier (east-west) and $4.6 \pm 1.3 \mathrm{~m}$ parallel to ice flow (north-south). The mean depth of these boreholes was $87 \mathrm{~m}$ min. $=23 \mathrm{~m}$; $\max .=132 \mathrm{~m} ; \sigma=41.5 \mathrm{~m})$. Contact with the bed was occasionally marked by a rapid fall in water level as equilibrium was reached with the subglacial water pressure at the base of the borehole. Less immediate connections were also recorded, with many boreholes connecting during the night within some days of being drilled. Once drilled, boreholes were isolated from supraglacial water inflow by channel diversion. However, minor inflow through the weathered surface ice layer could not be prevented. Water levels were monitored initially by manual sounding and subsequently, in 12 of the boreholes, by automated sensors (Fig. 2). The sensors measured water pressure, electrical conductivity (EC) and turbidity within a few tens of centimetres of the glacier bed. Their output was stored on microloggers Campbell Scientific CR-10) that recorded the means of 30 readings every $10 \mathrm{~min}$. Water pressures and ECs were calibrated against known values and are accurate to within $0.5 \mathrm{~m}$ of water head and $5 \mu \mathrm{S} \mathrm{cm}^{-1}$, respectively. ECs are presented as measured in water at c. $0^{\circ} \mathrm{C}$.

Borehole turbidities were measured by light-sensitive and light-emitting diodes that were separated by the sample. The difficulties involved in calibrating turbiditysensor records in terms of suspended-sediment concentrations are well-documented (e.g. Gippel, 1988; Stone and others, 1993). These data are therefore presented and interpreted predominantly in terms of "relative turbidity" $(T u[r])$, defined as

$$
T u[r]=\frac{(T u[c]-T u[s])}{T u[c]}
$$

where $T u[c]$ and $T u[s]$ are the turbidity signals recorded in clear water and the sample, respectively. Clear water, 


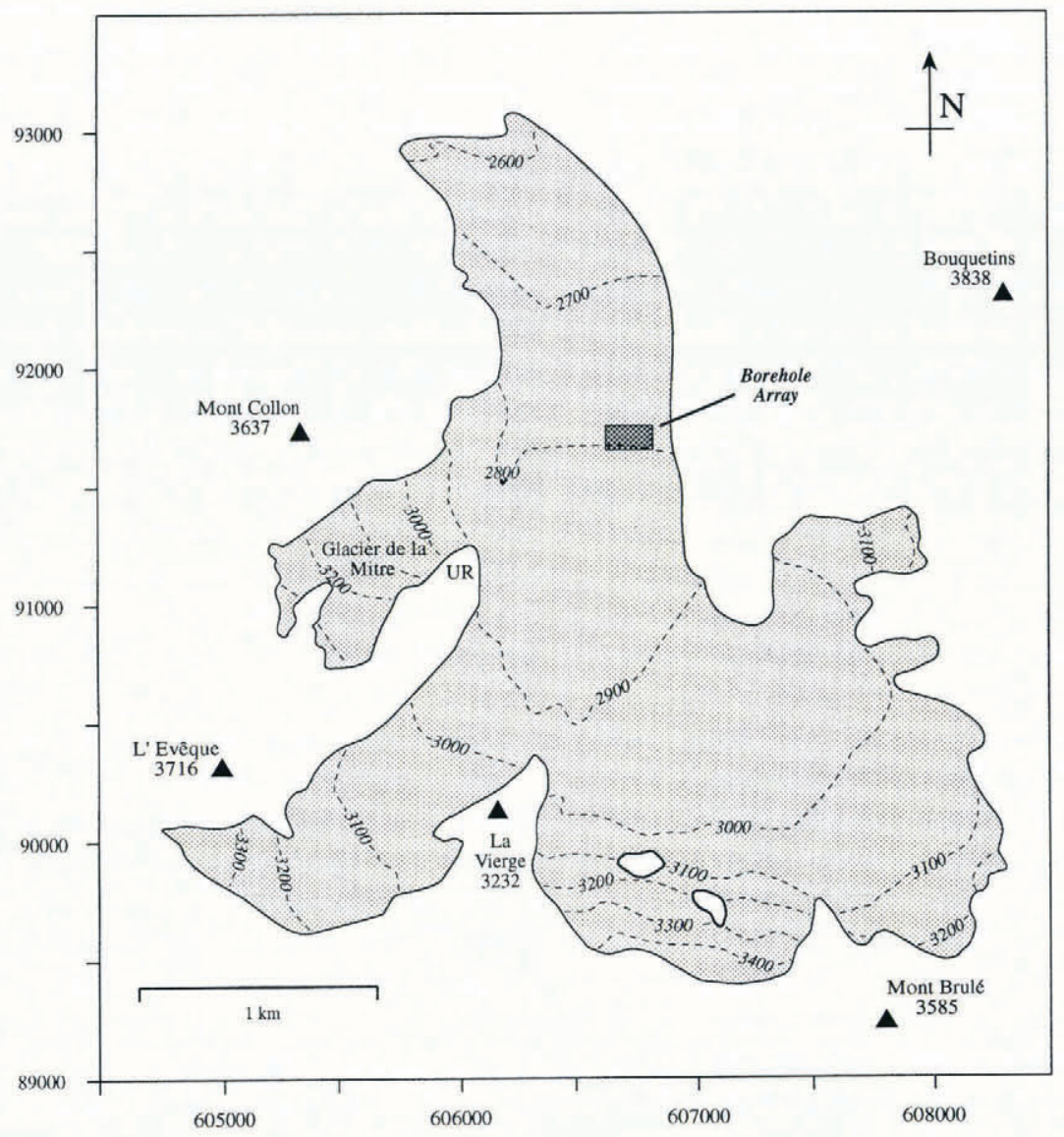

Fig. 1. Haut Glacier d'Arolla. The borehole array is located on the eastern side of the glacier tongue c. $1500 \mathrm{~m}$ from the terminus.

therefore, has a relative turbidity of 0 and opaque water a relative turbidity of 1 . However, turbidity sensors were also calibrated against suspended-sediment concentration (SSC) using the fine fraction $(<125 \mu \mathrm{m})$ of fluvially deposited sediments sampled from the proglacial area of Haut Glacier d'Arolla. These calibrations define a relationship of the form

$$
\mathrm{SSC}=28.4(T u[r]) \quad(R=1.00)
$$

where SSC is in $\mathrm{gl}^{-1}$ (Fig. 3). Despite the good fit of these data, the influence of variations in sediment grain-size and lithology remains unconstrained. Calibrated SSCs are therefore used only as an approximate indication of actual concentrations.

The data presented in this paper were recorded during a $7 \mathrm{~d}$ period of stable meteorological and hydrological conditions from 16 to 22 August 1993 (Julian Day [JD] 228-234). This time period was long enough to exclude daily meteorological variability and short enough to exclude seasonal trends in the hydraulic development of the subglacial drainage system. The latter of these forms the subject of another paper (paper in preparation by I. C. Willis and others). The data presented in this paper, and the interpretations based on them, are therefore considered to represent typical, late melt-season conditions at Haut Glacier d'Arolla.

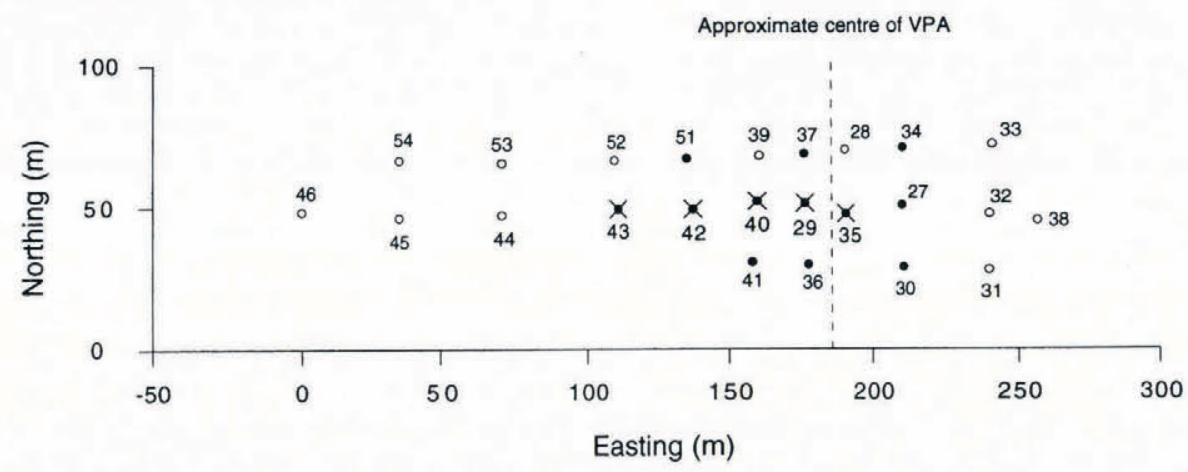

Fig. 2. The 1993 borehole array. Boreholes indicated by dots were monitored automatically and those indicated by circles were monitored manually (every 1-3h during daylight). Quantitative analysis presented in the text is based on data recorded in boreholes 35, 29, 40, 42 and 43 (crosses). 


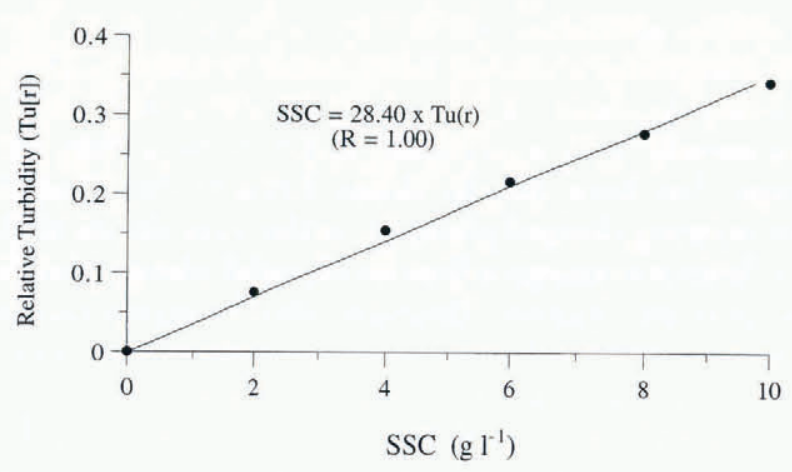

Fig. 3. Turbidity calibration curve for borehole sensors used during the 1993 field season. Sediments were recovered from fluvial deposits in the proglacial area of the glacier and were sieved to remove particles coarser than $125 \mu \mathrm{m}$ prior to calibration.

\section{DIURNAL SUBGLACIAL WATER-PRESSURE VARIATIONS}

Minimum daily borehole water levels and daily borehole water-level ranges have been interpolated spatially across the full borehole array (UNIRAS, 1990). The resulting surfaces for JD 229 demonstrate that much of this area of the glacier is characterized by subglacial water pressures that are high (approaching overburden pressure; Fig. 4a) and diurnally constant (Fig. 4b). However, the surfaces are clearly bisected by an axis, greater than $100 \mathrm{~m}$ wide and aligned sub-parallel to the general direction of ice flow, that is characterized by low minimum water pressures and large pressure variations. The centre of this "variable pressure axis" (VPA) passes through the borehole array at an easting of c. $185 \mathrm{~m}$; close to borehole 36 in the southern transect, between boreholes 35 and 29 in the middle transect and between boreholes 37 and 28 in the northern transect (Fig. 2).

Subglacial water pressures have also been investigated using time series of water levels recorded in boreholes 35 , 29, 40, 42 and 43 in the middle transect (Fig. 5). These records confirm a progressive drop in minimum water level and an increase in diurnal water-level range towards the centre of the VPA. Water levels in the two boreholes located closest to the centre of the VPA (boreholes 35 and 29) rise to within $10 \mathrm{~m}$ of the ice surface during the day and fall to the glacier bed for some hours overnight. These temporal variations take the general form of quasisinusoidal cycles, with a wavelength of $1 \mathrm{~d}$ and a phase relationship that lags c. $2 \mathrm{~h}$ behind glacier-surface air temperature. Closer inspection of the form of these cycles reveals a systematic asymmetry, with steep rising and attenuated falling limbs.

\section{Interpretation}

The water-pressure characteristics and orientation of the VPA are consistent with the location of a hydraulically efficient subglacial channel at its centre. In contrast,
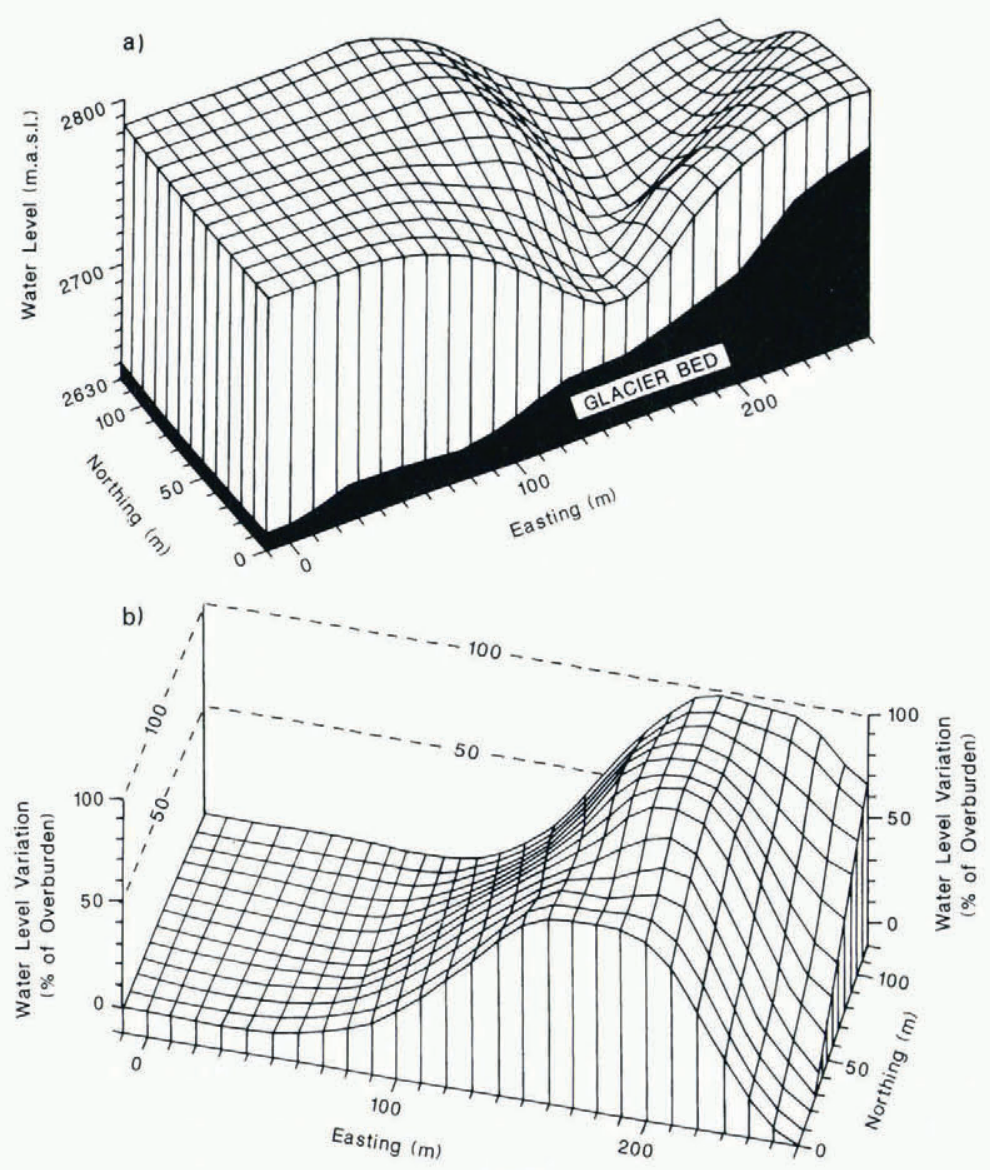

Fig. 4. Interpolated subglacial water-pressure surfaces for the full borehole array for fD 229, 1993: (a) minimum water level ( $m$ a.s.l.); (b) water-pressure variation (percentage of overburden). 
water pressures adjacent to the VPA are uniform and high-standing, indicating the presence of a widespread and less efficient drainage system. The parabolic crosssectional form of the VPA indicates that the two systems interact hydraulically and are possibly transitional, over tens of metres.

The nature of this hydraulic interaction may be investigated on the basis of diurnal water-level variations recorded across the middle borehole transect (Fig. 5). Water levels (in $\mathrm{m}$ a.s.1.) in boreholes 35 and 29, located close to the centre of the VPA, rise above and fall below those in boreholes 40, 42 and 43 each day. A diurnally reversing hydraulic gradient therefore exists between the channel and the surrounding glacier bed. Reconstructions of the direction and magnitude of this gradient between adjacent boreholes located to the west of the channel (Fig. 6) indicate that water is driven laterally out from the channel in the early afternoon and back to it overnight. The magnitude of the hydraulic gradient also diminishes with distance from the channel, as would the velocity of the consequent water flows under a uniform basal hydraulic configuration. The relatively minor diurnal water-pressure variations recorded in boreholes 42 and 43 suggest that the influence of these channel-initiated water flows decays rapidly over some tens of metres. No waterlevel variations were apparent in boreholes 44,45 or 46 , each of which was monitored manually several times a day. Even though these boreholes reached the glacier bed, water levels in them remained high and constant. Although such boreholes are "connected" to the subglacial hydrological system, the local capacity of that system may be inadequate to transmit water away from their bases rapidly enough to drain surface meltwater inputs. Water levels in such boreholes may not, therefore, reflect accurately the magnitude of local subglacial waterpressure variations. Such boreholes may fill with water during drilling and never subsequently drain to their equilibrium levels.

The asymmetric form of the borehole water-pressure time-series records (Fig. 5) may also reflect the nature of these lateral subglacial water flows. Alley (in press) argues that asymmetry arises in such systems because variations in effective pressure result in flow paths opening up first and closing down first at the channel boundary. Thus, according to Alley, cavities at the ice-bedrock interface progressively open up as water is driven away from the channel but have already closed down at the channel (due to falling channel pressures) as the water drains back to it. Return drainage is thereby impeded relative to outflow from the channel. Although Alley envisages such a process in terms of water flow through a film-cavity system over bedrock, our data suggest that similar cycles occur at Haut Glacier d'Arolla, which is underlain by unconsolidated sediments. Asymmetry in lateral water flows beneath such soft-bedded glaciers may reflect the effects of variable channel-marginal effective pressures on sediment consolidation rather than (or as well as) the capacity of flow pathways at the ice-substrate interface.

The significance of the diurnal, transverse water fluxes at Haut Glacier d'Arolla may be investigated on the basis of subglacial water-quality records across the middle borehole array (Fig. 7). Time series of basal EC recorded in boreholes 29, 40 and 42 have been compared with the hydraulic gradient between boreholes 29 and 40 for JD 229 and 230 (Fig. 7a). Borehole 29 is characterized by a strong diurnal EC cycle, rising gradually to c. $20 \mu \mathrm{S} \mathrm{cm}^{-1}$ overnight and falling rapidly to c. $2 \mu \mathrm{S} \mathrm{cm}^{-1}$ in the late morning. This pulse of solute-poor water represents the new day's melt wave arriving (from the channel) at borehole 29 as the hydraulic gradient is established from this borehole towards borehole 40 (Fig. 7a). The low EC of this water indicates, first, that the channel transports locally derived, surface meltwater at this time and, secondly, that little solute has been acquired during flow from the channel to borehole 29. In contrast, the high-EC signal recorded overnight in borehole 29 coincides with waters flowing back to the channel under the reversed hydraulic gradient. These waters have acquired solute within the distributed drainage system. ECs at the base of borehole 40 are generally higher $\left(15-20 \mu \mathrm{S} \mathrm{cm}^{-1}\right)$ and less variable than those at the base of borehole 29 , suggesting less subglacial hydrological mixing and longer water-rock contact times beneath the former. However, a distinct fall in EC is recorded at the base of borehole 40 during the

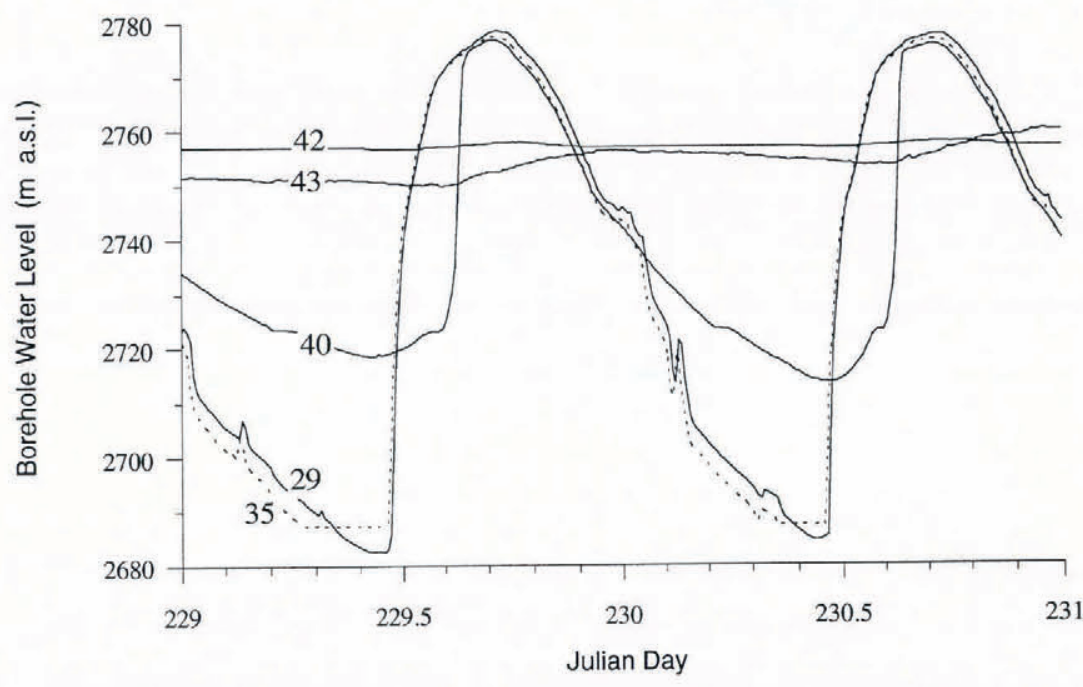

Fig. 5. Water-level time series recorded in boreholes across the middle transect on $7 D 229$ and 2301993. 
a )
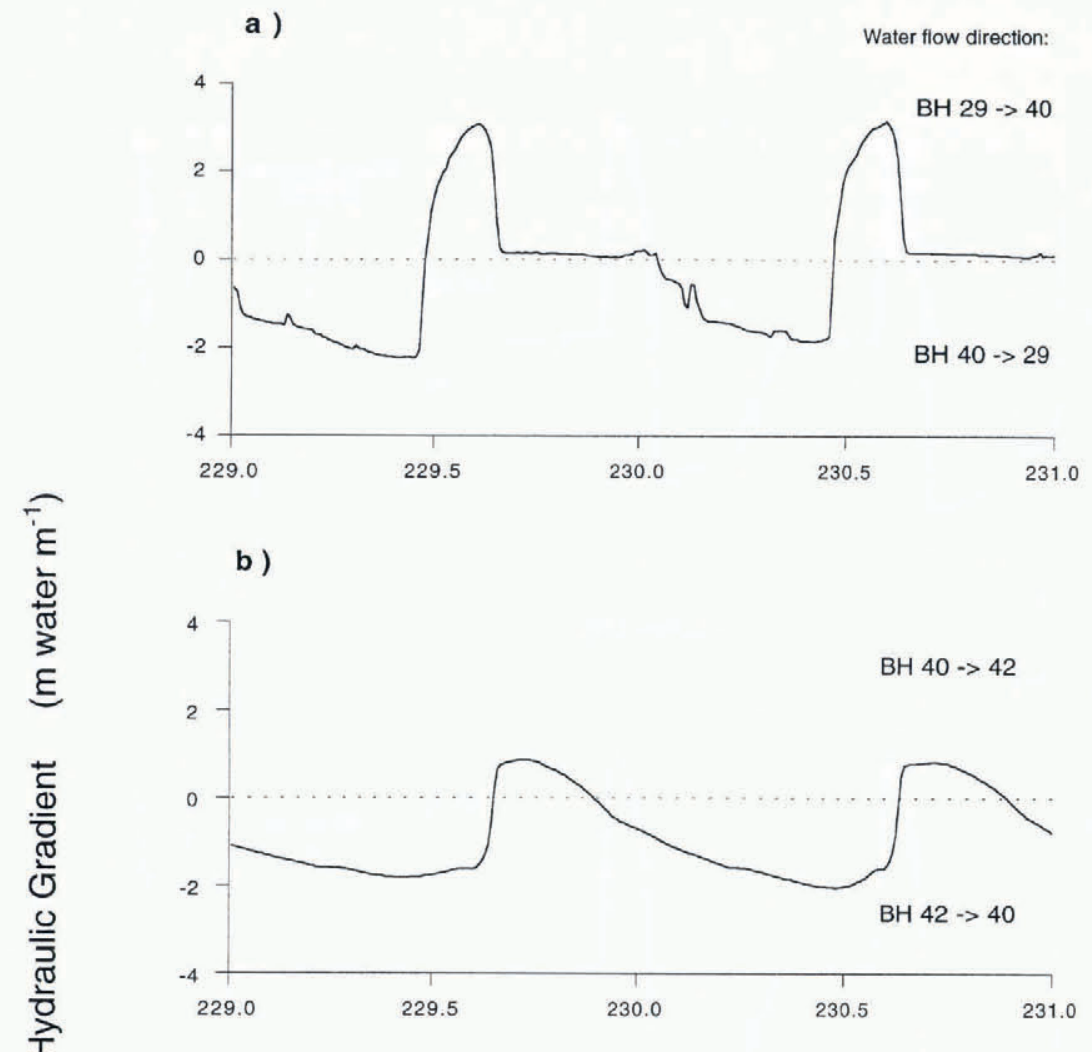

c)

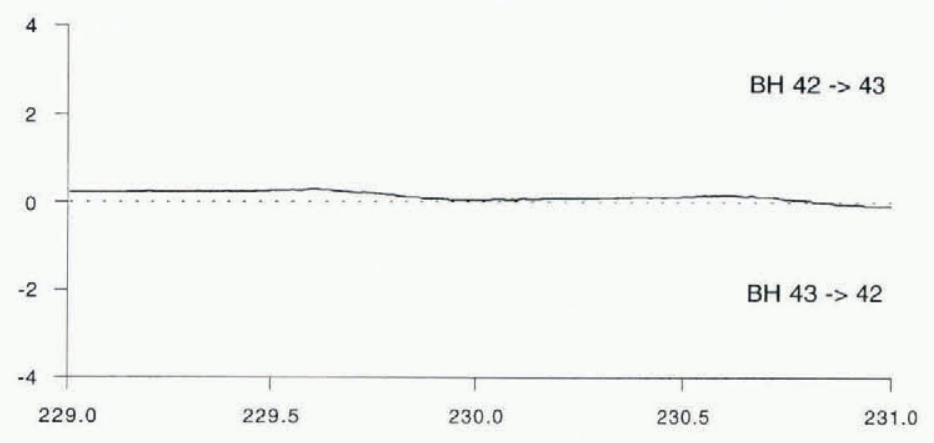

Julian Day

Fig. 6. Hydraulic gradients, calculated by linear interpolation, between borehole pairs across the middle transect on fD 229 and 230 1993: (a) borehole 29 to borehole 40, (b) borehole 40 to borehole 42 and (c) borehole 42 to borehole 43. (Calculations are based on borehole separation as surveyed at the glacier surface. Inclinometry suggests that these distances may be $\pm c .20 \%$ of borehole separation at the glacier bed. The magnitude of the reconstructed hydraulic gradients may therefore also be \pm c. $20 \%$ ).

afternoon. If we assume that this event reflects the arrival of the same low-EC pulse that is recorded in borehole 29 , then the approximate velocity of that pulse may be calculated from the time it takes to pass between the two boreholes: $0.24 \mathrm{~d}\left(2.1 \times 10^{4} \mathrm{~s}\right)$ on JD 229. The two boreholes are c. $16 \mathrm{~m}$ apart, indicating a mean flow velocity between them of c. $67 \mathrm{~m} \mathrm{~d}^{-1}\left(8 \times 10^{4} \mathrm{~m} \mathrm{~s}^{-1}\right)$. No such pronounced EC variations were recorded in either borehole 42 or borehole 43 .

Borehole turbidity-time series provide further evidence for diurnal subglacial water flows across the VPA. Reversals in the hydraulic gradient between boreholes 29 and 40 are coincident with turbidity pulses in both boreholes (Fig. 7b), indicating that the diurnal water flows are responsible for mobilizing fine sediments. However, the two turbidity cycles are out of phase and peak turbidities in borehole 29 are an order of magnitude higher than in borehole 40. These differences may be interpreted in terms of the source areas and relative amounts of sediment involved. During the early afternoon, when the hydraulic gradient drives water away from the channel, clear water is recorded at the base of borehole $29(T u[r]<0.001)$ and a (relatively) turbid pulse is recorded at the base of borehole 40 $(T u[r]>0.002)$. In contrast, when the reversed hydraulic gradient drives water back to the channel overnight, a prominent turbidity peak is recorded in borehole 29 $(T u[r]=$ c. 0.07$)$ and very low turbidities are recorded in borehole $40(T u[r]=$ c. 0.0005$)$. These patterns suggest, first, that the rate of water flow diminishes away from the channel such that, by borehole 40 , only relatively low suspended-sediment concentrations are recorded, and 

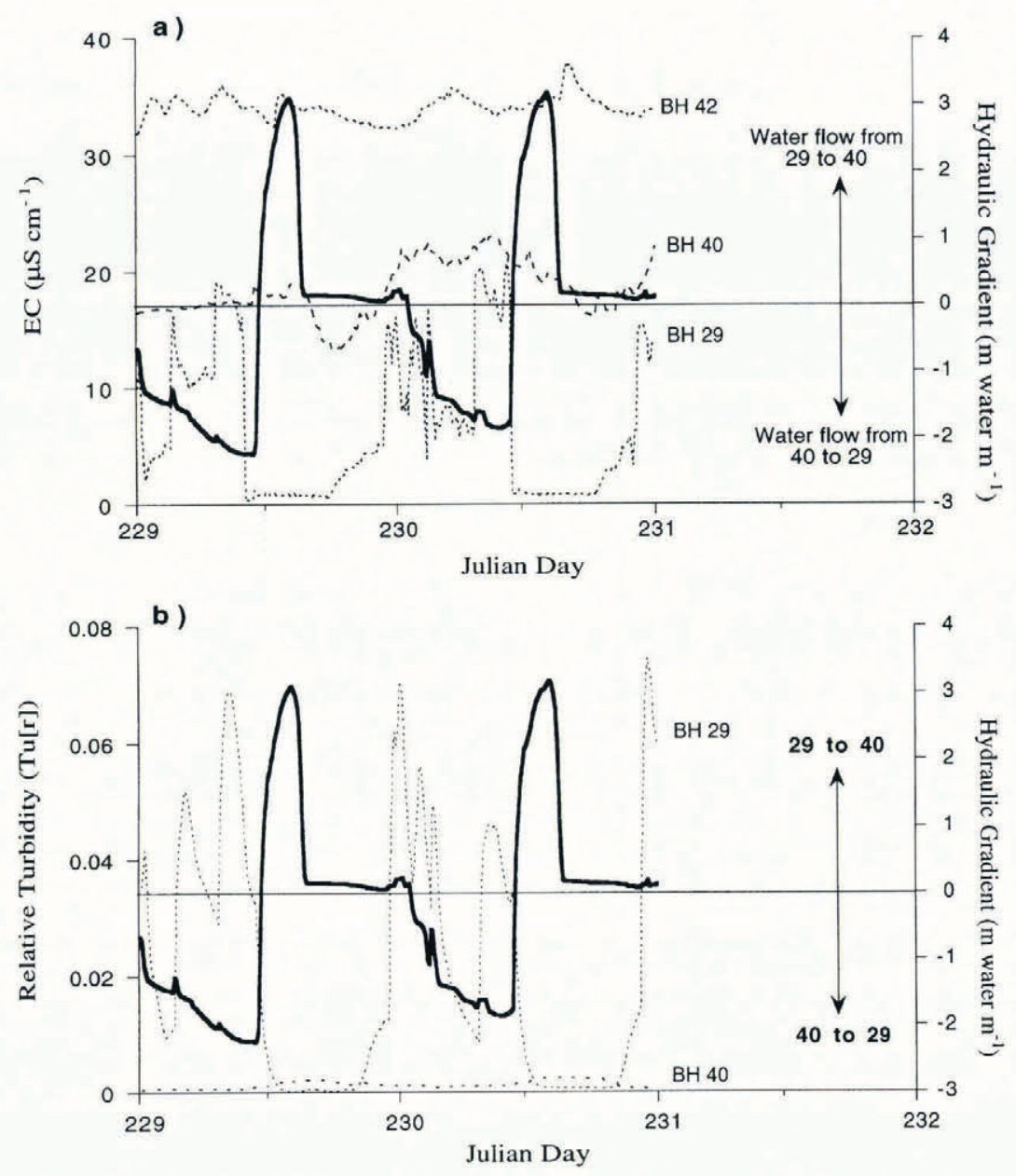

Fig. 7. Comparisons of the hydraulic gradient (heavy lines) calculated between boreholes 29 and 40 with (a) ECs recorded in boreholes 29, 40 and 42 and (b) relative turbidities recorded in boreholes 29 and 40 on $7 D 229$ and 2301993.

secondly, that waters returning to the channel are more turbid than those leaving it. Substitution of these data into Equation (2) suggests that, at borehole 29, waters leaving the channel in the morning have a SSC of $<0.1 \mathrm{~g} \mathrm{l}^{-1}$, while those returning to it overnight have a SSC c. $1-10 \mathrm{~g} \mathrm{l}^{-1}$. A net transfer of fine debris towards the channel is therefore inferred, with peak transfer rates occurring during the descending limb of the diurnal flow cycle. Overnight bulk meltwater suspended sediment yields may therefore comprise debris supplied principally by lateral water fluxes returning to subglacial channels. The nature of this erosion depends largely on the precise hydraulic configuration of the distributed system flow pathways. In the absence of evidence to the contrary, we adopt the working hypothesis that this occurs as porewater flow through the subglacial sediment layer. The permeability of such a layer may be investigated quantitatively on the basis of the speed and amplitude of water-pressure waves as they propagate through it.

\section{THE HYDRAULIC DIFFUSIVITY OF THE SUB- GLACIAL SEDIMENT LAYER}

Borehole data from Haut Glacier d'Arolla indicate that diurnal pressure waves are initiated at the centre of the
VPA and migrate laterally through the surrounding distributed system. Standard heat-flow theory (Ingersoll and others, 1954; Carslaw and Jaeger, 1959) provides analytical solutions that relate the propagation velocity (Fountain, 1994) and the amplitude attenuation of these pressure waves to the hydraulic conductivity of the sediments through which they migrate. According to this analysis, the driving pressure is treated as a boundary condition that varies as a harmonic function of time and the glacier bed is treated as a uniform half-solid with a steady water pressure at infinity.

\section{Pressure-wave propagation velocity}

The propagation velocity of a subglacial pressure change may be related to the frequency of the initiating pressure fluctuation and the hydraulic conductivity and specific storage of the sediments through which the wave passes. The time $t$ it takes for a pressure inflection to arrive at a point of distance $x$ from the channel is given by

$$
t=x \sqrt{\frac{S_{\mathrm{s}}}{2 \omega K}}
$$

where $S_{\mathrm{s}}$ is specific storage of the sediments (defined as the volume of water released from saturated storage by a 
unit volume of material under a unit decline of hydraulic head; $\left.\mathrm{m}^{-1}\right) ; \omega$ is the angular frequency of the periodic boundary condition $\left(2 \pi / t=7.27 \times 10^{-5} \mathrm{~s}^{-1}\right.$ for a diurnal cycle) and $K$ is the hydraulic conductivity of the sediments $\left(\mathrm{ms}^{-1}\right)$. Since both $K$ and $S_{\mathrm{s}}$ are related to the material properties of the sediments, we base our analysis on the ratio parameter hydraulic diffusivity (D) defined as

$$
D=\frac{K}{S_{\mathrm{s}}}
$$

(Freeze and Cherry, 1979, p.61; $\mathrm{m}^{2} \mathrm{~s}^{-1}$ ). Solving Equation (3) for $D$ gives

$$
D=\frac{x^{2}}{\left(2 \omega t^{2}\right)}
$$

Equation (5) can be solved in one dimension across the middle borehole transect using the recorded pressure-wave arrival times at boreholes 35, 29, 40, 42 and 43. For the purpose of these calculations, we assume that borehole 35 marks the westward margin of the channel. We therefore take distance $x=0$ at borehole 35 and $t=0$ as the time at which the direction of pressure change reverses in this borehole. Plotting the mean time of arrival of diurnal pressure inflections (maxima and minima) along this transect for the $7 \mathrm{~d}$ period, JD 228-234, reveals a quasiexponentially increasing delay in arrival time away from the channel (Fig. 8a). The diurnal pressure wave therefore propagates at a progressively lower velocity as it migrates away from the channel. These pressure-wave velocities may be compared with that predicted under the assumption of a constant hydraulic diffusivity for the sediments underlying the VPA (Fig. 8b). Substituting a typical value of $D$ for subglacial sediments $\left(3.4 \times 10^{-3} \mathrm{~m}^{2} \mathrm{~s}^{1}\right.$; Murray and Clarke, 1995; Table 1) into Equation (5) yields a propagation velocity $(x / t)$ of c. $7 \times 10^{-4} \mathrm{~ms}^{-1}$ (Fig. $\left.8 \mathrm{~b}\right)$. This velocity contrasts markedly with those recorded across the VPA: measured pressure-wave velocities are, first, markedly higher than $7 \times 10^{-4} \mathrm{~ms}^{-1}$, suggesting that subglacial

Table 1. Reported values of hydraulic conductivity and specific storage for typical subglacial sediments

\begin{tabular}{|c|c|c|}
\hline $\begin{array}{l}1.1 \times 10^{-6} \text { to } \\
22 \times 10^{-6}\end{array}$ & - & Boulton and Dent \\
\hline $10^{-4}$ to $10^{-7}$ & - & Fountain (1994) \\
\hline $10^{-6}$ to $10^{-12}$ & $10^{-4}$ to $10^{-7}$ & $\begin{array}{l}\text { Freeze and Cherry } \\
(1979)\end{array}$ \\
\hline $2.2 \times 10^{8}$ & $6.4 \times 10^{-6}$ & $\begin{array}{l}\text { Murray and Clarke } \\
\text { (in press) }\end{array}$ \\
\hline $10^{-8}$ to $10^{-9}$ & - & Waddington (1993) \\
\hline $2 \times 10^{-9}$ & - & $\begin{array}{l}\text { Engelhardt and } \\
\text { others }(1990)\end{array}$ \\
\hline $1.3 \times 10^{-7}$ & - & $\begin{array}{l}\text { Iverson and others } \\
\text { (1994) }\end{array}$ \\
\hline
\end{tabular}

$\begin{array}{ccc}\begin{array}{c}\text { Hydraulic conductivity } \\ \mathrm{m} \mathrm{s}^{-1}\end{array} & \text { Specific storage } \\ \mathrm{m}^{-1} & \text { Source }\end{array}$

sediments beneath the VPA are characterized by a higher hydraulic diffusivity than typical glacial tills, and secondly, decrease away from the channel, suggesting an associated decrease in the hydraulic diffusivity of the subglacial sediment layer. Fitting a curve to these data indicates that the hydraulic diffusivity $(D)$ of the layer decreases exponentially with distance $(x$; in $\mathrm{m})$ according to

$$
D=43.5 \mathrm{e}^{(-0.091 x)} \quad(R=0.99)
$$

(Fig. 8c). Solving Equation (6) for $D$ at the channel margin $(x=0)$ and at the "edge" of the VPA $(x=70)$, yields hydraulic diffusivities of $4 \times 10^{1} \mathrm{~m}^{2} \mathrm{~s}^{-1}$ and $7 \times 10^{-2}$ $\mathrm{m}^{2} \mathrm{~s}^{-1}$, respectively. The range of hydraulic conductivities associated with these diffusivities may be approximated by substituting a typical value of $S_{\mathrm{s}}$ for subglacial sediments $\left(6.4 \times 10^{-6} \mathrm{~m}^{-1}\right.$; Murray and Clarke, 1995; Table 1) into Equation (4). The resulting hydraulic conductivities are $3 \times 10^{-4} \mathrm{~m} \mathrm{~s}^{-1}$ for sediments located close to the channel and $5 \times 10^{-7} \mathrm{~m} \mathrm{~s}^{-1}$ for sediments located c. $70 \mathrm{~m}$ away (bearing in mind that the assumption of constant $S_{\mathrm{s}}$ may reduce the accuracy of the analysis by an order of magnitude (Freeze and Cherry, 1979 , p. 55)). Whilst the latter value is typical of Darcian flow through subglacial till (Table 1), the former is more typical of flow through clean sand (Freeze and Cherry, 1979, p. 29).

Analysis of the propagation velocity of the diurnal pressure wave at Haut Glacier d'Arolla therefore indicates that the hydraulic diffusivity of the subglacial sediment layer increases markedly towards the centre of the VPA. This is consistent with the progressive removal of fines from such a layer by diurnal water flows that are initiated at, and return to, a subglacial channel located at the centre of the VPA.

\section{Pressure-wave amplitude}

The hydraulic diffusivity $(D)$ of the subglacial sediment layer may also be estimated from the amplitude attenuation of the diurnal pressure wave as it propagates across the VPA. Following Carslaw and Jaeger (1959), the decay of wave amplitude $(a)$ with distance $(x)$ from the channel is given by

$$
\frac{a(x)}{a(0)}=\mathrm{e}^{\left(-2 x \sqrt{\frac{\omega}{8 D}}\right)} .
$$

This relation may be used to predict the amplitude attenuation of diurnal pressure waves as they migrate across the middle borehole transect (boreholes 35, 29, 40, 42 and 43 ) under two assumptions; first, that the hydraulic diffusivity of the underlying sediments is uniform ( $\left.D=3.4 \times 10^{-3} \mathrm{~m}^{2} \mathrm{~s}^{-1}\right)$ and, secondly, that the hydraulic diffusivity of the underlying sediments decreases away from the channel in accordance with the propagation velocity of the diurnal pressure wave. Under the second scenario, $a(0)$ is redefined at each borehole according to the recorded amplitude and $D$ changes continuously across the VPA according to Equation (6). Predicted amplitude-attenuation patterns under the two scenarios are compared with those recorded across the transect on JD 234 (Fig. 9). None of the water levels fell below the sensors on this day, providing records of the full magnitude of the pressure- 


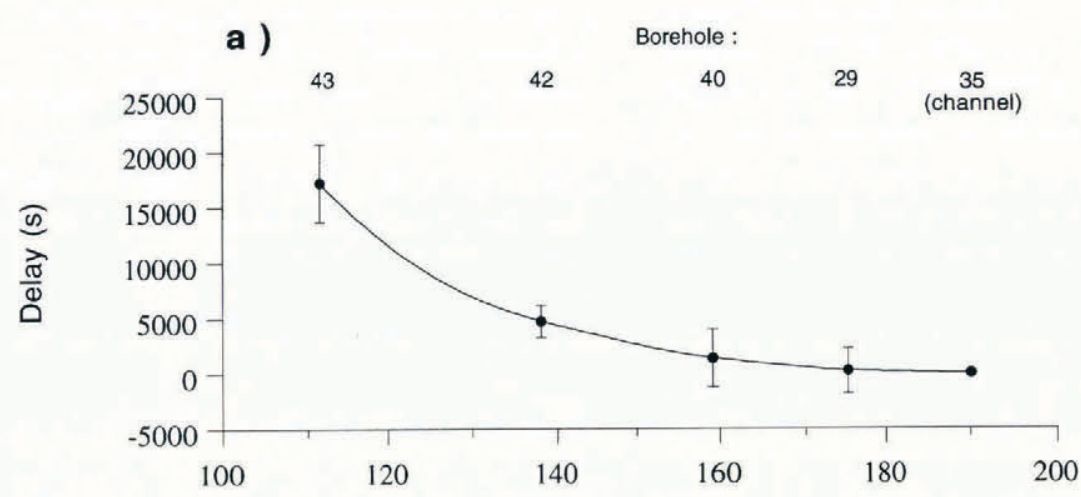

b)

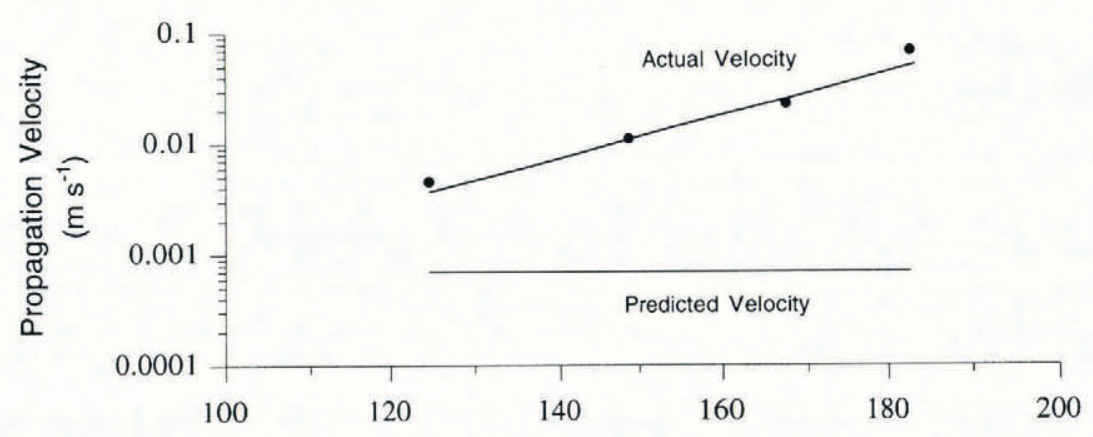

c)

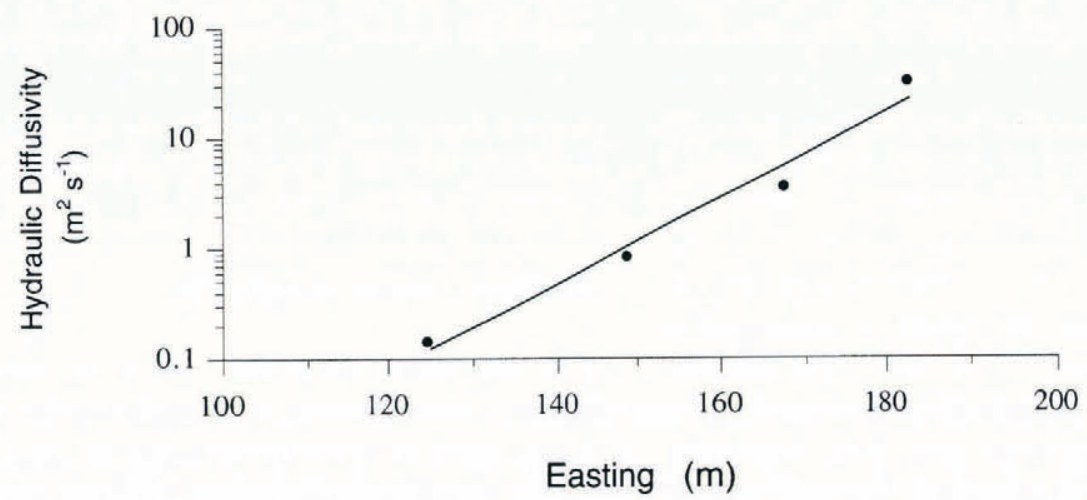

Fig. 8. Analysis of the propagation velocity of the diurnal pressure wave across the middle borehole transect (boreholes 35 , 29, 40, 42 and 43) for $7 D$ 228-234 1993: (a) time delay to arrival of pressure-wave inflections following initiation at borehole 35 (error bars $=1 \sigma) ;(b)$ associated propagation velocity (the velocity predicted for typical subglacial tills (explained in text) is shown for comparison); (c) calculated variation in hydraulic diffusivity $(D)$.

wave cycles in all boreholes. The assumption of homogeneous subglacial sediments yields amplitudes that are similar to those recorded in boreholes 40-43, but which decay too rapidly close to the centre of the VPA (Fig. 9a). This comparison therefore indicates that the hydraulic diffusivity of the subglacial sediment layer between the channel and borehole 40 is higher than that of typical subglacial sediments. Indeed, with the exception of borehole 42, recorded pressure-wave amplitudes correspond much better with those predicted on the basis of an exponential decrease in diffusivity away from the channel (Fig. 9b). However, a much smaller amplitude is recorded in borehole 42 than is predicted. The hydrological system beneath this borehole may be unable to transport the water flux that is required to reflect accurately the magnitude of the subglacial pressure wave. This anomalous behaviour suggests that the analysis of pressure-wave amplitudes (that is, based on water levels in open boreholes) may be susceptible to local variations in the capacity of the subglacial hydrological system. In contrast, the analysis of pressure-wave velocities (based on the timing of a pressure change) is less sensitive to such variations since wave propagation does not require significant water transfer. This interpretation is supported by the consistency of the timing of the pressure variation recorded in borehole 42 with arrival times in boreholes 40 and 43 that are adjacent to it (above).

Analysis of both pressure-wave velocities and pressurewave amplitudes at Haut Glacier d'Arolla suggest a systematic increase in hydraulic diffusivity (to levels 
significantly above those of typical subglacial sediments) close to the centre of the VPA. This increase is interpreted in terms of a coarsening of the subglacial sediment layer. This inference may be assessed by comparing the hydraulic conductivity of a channel-marginal subglacial sediment sample (recovered from a basal cavity at Haut Glacier d'Arolla; Fig. 10) with that determined on the basis of the pressure-wave analyses. The hydraulic conductivity $\left(K\right.$ in $\left.\mathrm{ms}^{-1}\right)$ of this sample may be approximated from its effective grain-size the diameter at which $10 \%$ by weight of the particles are finer than $d_{10}$ in $\mathrm{mm}$ ) according to

$$
K=\frac{\left(a d_{10}^{2}\right)}{100}
$$

where $A$ is a coefficient with a value of c. $1\left(\mathrm{~m}^{-1} \mathrm{~s}^{-1}\right)$ (Freeze and Cherry, 1979, p. 350). The effective grainsize $\left(d_{10}\right)$ of the sample is c. $0.3 \mathrm{~mm}$, indicating (from Equation (8)) a hydraulic conductivity of c. $9 \times 10^{-4} \mathrm{~m} \mathrm{~s}^{-1}$. This hydraulic conductivity is consistent with that determined for channel-marginal sediments on the basis of the diurnal pressure-wave propagation velocity and amplitude attenuation $\left(3 \times 10^{-4} \mathrm{~ms}^{-1}\right.$; above $)$.

\section{SUMMARY AND DISCUSSION}

Diurnal water-level variations in boreholes in the ablation area of Haut Glacier d'Arolla indicate the late melt-season presence of a variable pressure axis (VPA) that is aligned broadly parallel to the direction of ice flow. This axis is characterized by a gradual rise from low minimum diurnal water pressures and high diurnal water-pressure variations at its centre to high minimum diurnal water pressures and low diurnal water-pressure variations at its margins, about $70 \mathrm{~m}$ away. These patterns indicate the presence of a major subglacial channel (located at the centre of the VPA) that is bounded by, and interacts with, an extensive "distributed" hydrological system. Reconstructed subglacial hydraulic gradients suggest that this interaction is driven by large diurnal water-pressure variations within the channel: high pressures in the day force water out from the channel, and into the adjacent distributed system, and low channel pressures overnight drive that water back. Analyses of the velocity and amplitude attenuation of the associated diurnal pressure waves indicate that the hydraulic efficiency of the distributed system increases markedly close to the channel. In the foregoing analysis, we have postulated that these flows occur by permeating the subglacial sediment layer that underlies the VPA. Whilst such flows must occur where a hydraulic gradient acts on saturated, permeable sediments, the apparent increase in hydraulic diffusivity close to the channel may also be interpreted in terms of flow concentration at the ice sediment interface. Such concentration may take three forms: first, as film flow at the ice till interface (Weertman and Birchfield, 1983), secondly, as porewater flow through coarser, and therefore more

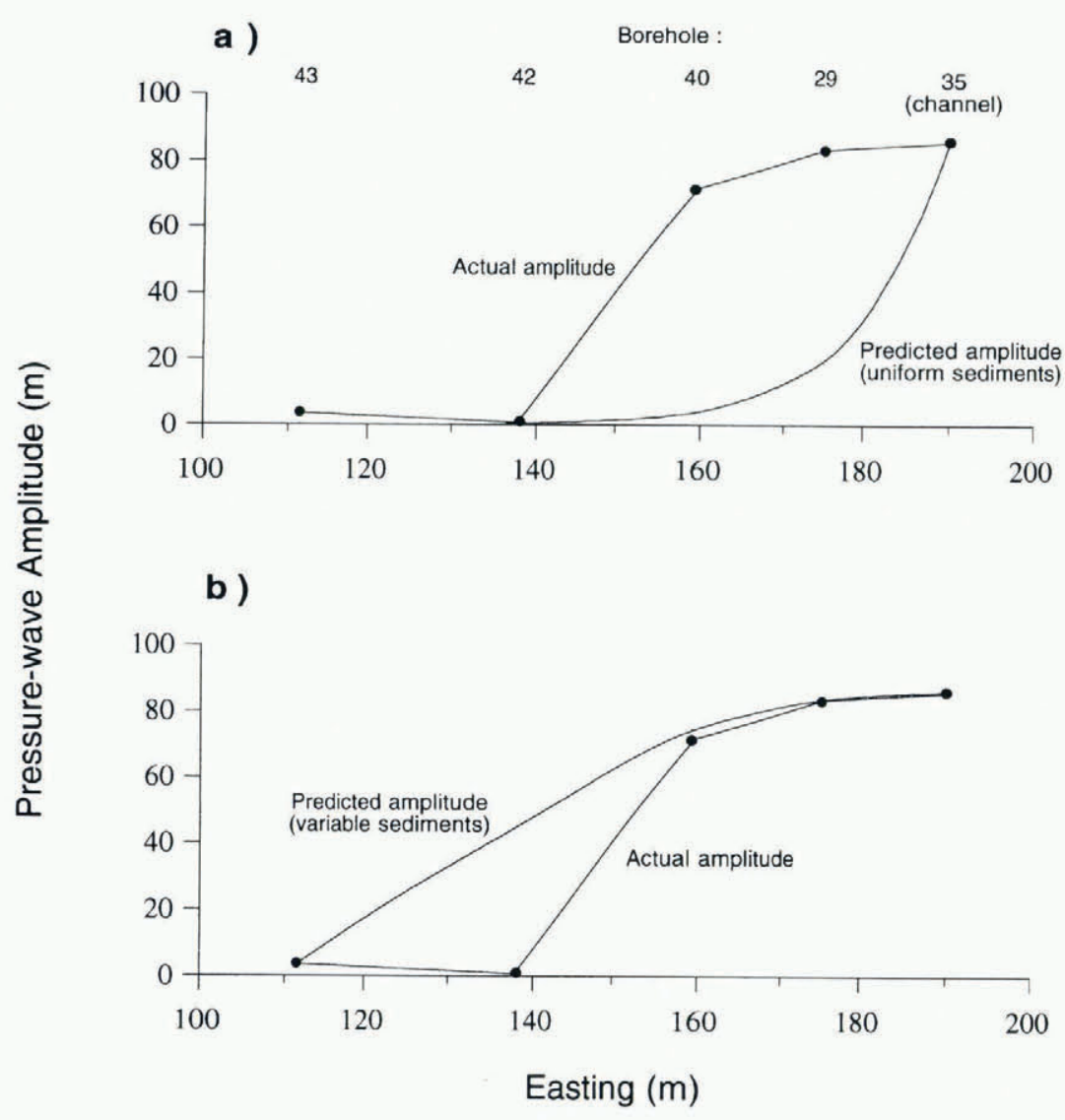

Fig. 9. Comparison of the amplitude attenuation of the diurnal pressure wave recorded across the middle borehole transect (boreholes 35, 29, 40, 42 and 43) on $J D 234$ with that predicted for subglacial sediments with (a) a uniform hydraulic diffusivity $\left(3.4 \times 10^{-3} \mathrm{~m}^{2} \mathrm{~s}^{-1}\right)$ and $(b)$ a hydraulic diffusivity that decreases with distance from the channel (according 10 Equation (6); see text). 
hydraulically transmissive, clasts at the upper surface of the subglacial sediment layer (Fountain, 1994), and thirdly, as flow through a network of small channels located at the ice-sediment interface (Walder and Fowler, 1994). Although any of these configurations may exist beneath the VPA at Haut Glacier d'Arolla, no independent evidence is currently available to suggest that this is the case. In contrast, the correspondence of the hydraulic conductivity of a channel-marginal subglacial sediment sample with that determined from the pressure-wave analyses suggests that the inferred hydraulic diffusivities may be accounted for by porewater flow alone.

Lateral, diurnal water flows at the glacier bed involve the temporary storage of waters in the distributed hydrological system, the transport of subglacial debris and systematic variations in the pattern of subglacial water pressures. These may have important implications for glacier erosion, hydrochemistry and motion.

\section{Implications for glacier erosion}

It has long been recognized that pore-water flow has the capacity to eluviate fine debris through unconsolidated sediments (e.g. Ingles, 1968). Boulton and Dent (1974) linked vertical grain-size variations in proglacial tills at Breiðamerkurjökull, Iceland, to eluviation by permeating rain water, whilst Clarke (1987) suggested that subglacial pore-water flows could result in lateral variations in the texture of the sediment layers through which they pass. We believe that evidence from Haut Glacier d'Arolla provides the first empirical support for this process of subglacial erosion. Borehole-turbidity pulses are synchronous with systematic changes in the direction of the subglacial hydraulic gradient and analyses of the propagation rate and amplitude attenuation of the diurnal pressure wave indicates that subglacial sediments are characterized by systematic transverse variations in hydraulic conductivity, varying from c. $10^{-4} \mathrm{~ms}^{-1}$ at the channel margin to c. $10^{-7} \mathrm{~m} \mathrm{~s}^{-1} 70 \mathrm{~m}$ away. These values suggest, first, that fine material has been removed from sediments underlying the borehole array and, secondly, that such removal is greatest close to the subglacial channel, along which fines may be transported to the glacier portal. The spatial extent of this erosion may be approximated by the area of the glacier bed affected by the permeating diurnal water flux. Borehole EC and turbidity records from Haut Glacier d'Arolla indicate that such a zone may be about $20-40 \mathrm{~m}$ wide. Boreholeturbidity records further suggest that waters returning from this zone to the central channel may transport fine sediments at concentrations of $1-10 \mathrm{~g} \mathrm{l}^{-1}$.

\section{Implications for glacier hydrochemistry}

The occurrence of diurnal, lateral subglacial water flows suggests the presence of three subglacial weathering environments. First, waters flowing within melt-season conduits will be characterized by solute-acquisition signatures that are indicative of the dissolution of relatively high suspended-sediment concentrations for short periods (tens of minutes to hours). Secondly, waters flowing through sediments beneath the VPA will be characterized by solute loads that are acquired from in-situ subglacial sediments and (possibly) suspended sediments over some hours. These effects may be most evident in bulk meltwaters forming the recession limb of diurnal hydrographs, since that is when these cycled pore waters return to subglacial drainage channels and exit the glacier. Solute acquisition within the distributed system represents the third weathering environment, where waters are in contact with sediments containing a high proportion of reactive fines for periods of perhaps weeks to months. Such waters may exit the glacier relatively continuously, as an ionically concentrated "base-flow" component.

\section{Implications for glacier motion}

High subglacial water pressures increase basal sliding, either via slip at the ice bedrock (Iken and Bindschadler, 1986) or ice sediment (Iverson and others, 1995) interface or via the deformation of a subglacial sediment layer (e.g. Boulton and Hindmarsh, 1987). Our borehole investigations at Haut Glacier d'Arolla reveal that subglacial water pressures approach overburden within a band $50 \mathrm{~m}$ wide at the centre of the VPA (Fig. 4b) for some hours each day (Fig. 5) during the late melt season.

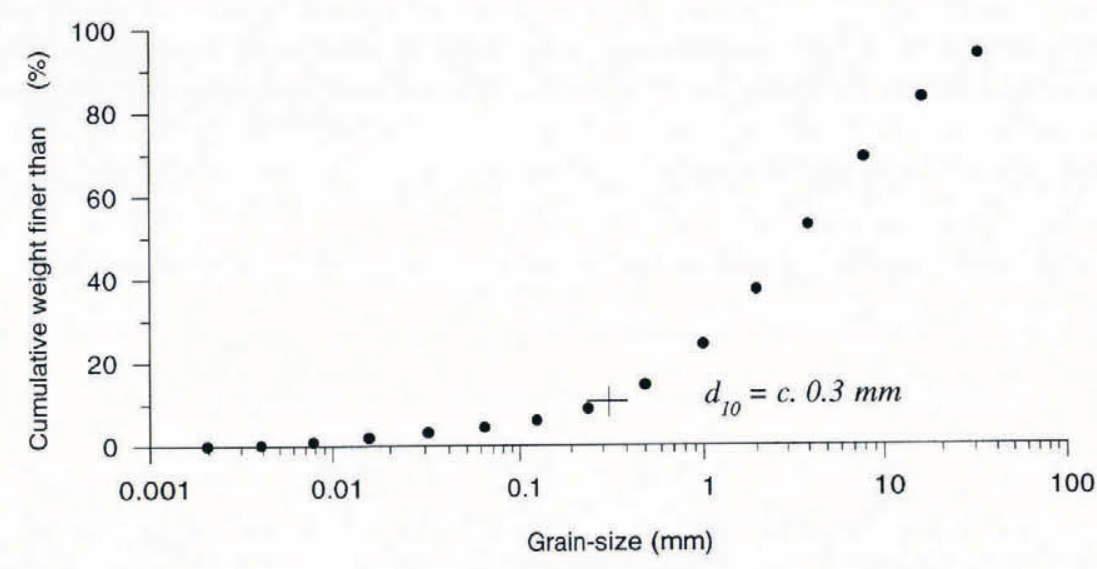

Fig. 10. Grain-size distribution of a near-channel subglacial till sampled from a cavity in the ablation area of Haut Glacier d'A rolla. Grain-size fractions were determined by dry-sieving from $-5 \phi$ to $3 \phi(320.125 \mathrm{~mm})$ and by laser granulometry from $3 \phi$ to $9 \phi$ (0.125-0.002 mm; Hubbard, 1992). 
Reconstructed subglacial hydraulic potentials indicate that two such channels drain the glacier for most of its length (Sharp and others, 1993), suggesting that these high transient subglacial water pressures affect c. $10 \%$ of this section of the glacier (which is c. $1 \mathrm{~km}$ wide). This proportion may increase down-glacier as the net meltwater flux increases and glacier width decreases. The inferred lateral variations in subglacial sediment texture may also influence glacier motion, since laboratory studies indicate that shear strength may be increased by the removal of fines (e.g. Rodine and Johnson, 1976).

Lateral subglacial water flows, such as those identified at Haut Glacier d'Arolla, therefore have time-dependent consequences for patterns of subglacial pore-water pressure and sediment texture (and therefore rheology). These influences may be reflected in high-resolution temporal and spatial variations in glacier motion.

\section{ACKNOWLEDGEMENTS}

We thank A. Hubbard and M. Tulley for their assistance in the field. Y. Bams and P. and B. Bournissen provided essential logistical support in Arolla. Additional logistical support was provided by M. Beytreyson of Grande Dixence S.A. The manuscript has been greatly improved by comments on an earlier draft by $\mathrm{R}$. Hooke, N. Iverson and A. Fountain. The research was funded by the U.K. Natural Environment Research Council grant GR3/ 8114 ) and the Royal Society.

\section{REFERENCES}

Alley, R.B. 1992. How can low-pressure channels and deforming tills coexist subglacially? 7. Glaciol., 38 128), 200-207.

Alley, R. B. In press. Toward a hydrologic model for computerized icesheet simulations. Hydrological Processes, Special Issue.

Boulton, G. S. 1974. Processes and patterns of glacial erosion. In Coates, D. R., ed. Glacial geomorphology. Binghamton, NY, State University of New York, 41-87.

Boulton, G.S. and D. L. Dent. 1974. The nature and rates of postdepositional changes in recently deposited till from south-east Iceland. Geogr. Ann., 56A (3-4), 121-134.

Boulton, G.S. and R. C. A. Hindmarsh. 1987. Sediment deformation beneath glaciers: rheology and geological consequences. J. Geophys. Res., 92 B9), 9059-9082.

Carslaw, H.S. and J. C. Jaeger. 1959. Conduction of heat in solids. Second edition. Oxford, Clarendon Press.

Clarke, G. K.C. 1987. Subglacial till: a physical framework for its properties and processes. 7. Geophys. Res., 92 B9), 90239036.

Engelhardt, H., N. Humphrey, B. Kamb and M. Fahnestock. 1990. Physical conditions at the base of a fast moving Antarctic ice stream. Science, 248 4951), 57-59.

Fountain, A.G. 1992. Subglacial water flow inferred from stream measurements at South Cascade Glacier, Washington, U.S.A. J. Glaciol., 38 128), 51-64.

Fountain, A. G. 1994. Borehole water-level variations and implications for the subglacial hydraulics of South Cascade Glacier, Washington State, U.S.A. J. Glaciol., 40 135), 293-304.

Freeze, R. A. and J. A. Cherry. 1979. Groundwater. Englewood Cliffs, NJ, Prentice-Hall.

Gippel, C.J. 1988. The effect of water colour, particle size and particle composition on stream water turbidity measurements. Kensington, University of New South Wales. University College. Department of Geography and Oceanography. (Working Paper 1988/3.

Hock, R. and R. LeB. Hooke. 1993. Evolution of the internal drainage system in the lower part of the ablation area of Storglaciaren, Sweden. Geol. Soc. Am. Bull., $105(4), 537-546$.

Hooke, R. LeB., T. Laumann and J. Kohler. 1990. Subglacial water pressures and the shape of subglacial conduits. f. Glaciol., 36 122), $67-71$.

Hubbard, B. P. 1992. Basal ice fabrics and their formation in the western Alps. Ph.D. thesis, University of Cambridge.

Iken, A. and R.A. Bindschadler. 1986. Combined measurements of subglacial water pressure and surface velocity of Findelengletscher, Switzerland: conclusions about drainage system and sliding mechanism. 7. Glaciol., 32 110), 101-119.

Ingersoll, L. R., O.J. Zobel and A. C. Ingersoll. 1954. Heat conduction. Madison, WI, etc., University of Wisconsin Press.

Ingles, O. G. 1968. Soil chemistry relevant to the engineering behaviour of soils. In Lee, I.K., ed. Soil mechanics: selected topics. London, Butterworths.

Iverson, N. R., P. Jansson and R. LeB. Hooke. 1994. In-situ measurement of the strength of deforming subglacial till. 7. Glaciol., 40 (36), 497-503.

Iverson, N. R., B. Hanson, R. LeB. Hooke and P. Jansson. 1995. Flow mechanism of glaciers on soft beds. Science, 267 (5194), $80-81$.

Kamb, B. 1987. Glacier surge mechanism based on linked cavity configuration of the basal water conduit system. 7. Geophys. Res., 92 B9), $9083-9100$.

Kamb, B. and E. LaChapelle. 1964. Direct observation of the mechanism of glacier sliding over bedrock. F. Glaciol., 5 38), 159-172.

Murray, T. and G. K. C. Clarke. In press. Black-box modeling of the subglacial water system. 7. Geophys. Res.

Nienow, P. W. 1994. Dye-tracer investigations of glacier hydrological systems. (Ph.D. thesis. University of Cambridge.

Nye, J. F. 1973. Water at the bed of a glacier. International Association of Scientific Hydrology Publication 95 (Symposium at Cambridge 1969 Hydrology of Glaciers), 189-194.

Rodine, J. D. and A.M. Johnson. 1976. The ability of debris, heavily freighted with coarse clastic materials, to flow on gentle slopes, Sedimenlology, 23, 213234.

Röthlisberger, H. 1972. Water pressure in intra- and subglacial channels. J. Glaciol., 11 (62), 177-203.

Seaberg, S. Z., J. Z. Seaberg, R. LeB. Hooke and D. W. Wiberg. 1988. Character of the englacial and subglacial drainage system in the lower part of the ablation area of Storglaciären, Sweden, as revealed by dye-trace studies. J. Glaciol., 34 117), 217-227.

Sharp, M. ,J. C. Gemmell and J. -L. Tison. 1989. Structure and stability of the former subglacial drainage system of Glacier de Tsanfleuron, Switzerland. Earth Surface Processes and Landforms, 14 2), $119-134$.

Sharp, M. and 6 others. 1993. Geometry, bed topography and drainage system structure of the Haut Glacier d'Arolla, Switzerland. Earth Surface Processes and Landforms, 18 (6), 557-571.

Stone, D.B., G. K.C. Clarke and E.W. Blake. 1993. Subglacial measurement of turbidity and electrical conductivity. J. Glaciol., 39 (132), $415-420$.

UNIRAS. 1990. Unimap 2000 users manual. Version 6. Soborg, Denmark. etc., UNIRAS Ltd.

Waddington, B.S. 1993. Hydraulic properties of subglacial sediment determined from the mechanical response of water-filled boreholes. (M.Sc. thesis, University of British Columbia.)

Walder, J.S. 1982. Stability of sheet flow of water beneath temperate glaciers and implications for glacier surging. J. Glaciol., 28 99), $273-$ 293.

Walder, J. S. 1986. Hydraulics of subglacial cavities. .J. Glaciol., 32 112), 439445.

Walder, J.S. and A. Fowler. 1994. Channelized subglacial drainage over a deformable bed. J. Glaciol., 40 (134), 3-15.

Walder, J. and B. Hallet. 1979. Geometry of former subglacial water channels and cavities. J. Glaciol., 23 89), 335-346.

Weertman, J. 1957. On the sliding of glaciers. J. Glaciol., 3 21), 33-38.

Weertman, J. 1972. General theory of water flow at the base of a glacier or ice sheet. Rev. Geophys. Space Phys., 10 1), 287-333.

Weertman, J. and G, E. Birchfield. 1983. Stability of sheet water flow under a glacier. J. Glaciol., 29 103), 374-382. 